University at Albany, State University of New York

Scholars Archive

University Libraries Faculty Scholarship

University Libraries

2020

\title{
21st Century Anthropology Scholarship: A Citation Analysis
}

Priscilla Seaman

University at Albany, State University of New York, pseaman@albany.edu

Sue A. Kaczor

University at Albany, State University of New York, skaczor@albany.edu

Follow this and additional works at: https://scholarsarchive.library.albany.edu/ulib_fac_scholar

Part of the Anthropology Commons

\section{Recommended Citation}

Seaman, Priscilla and Kaczor, Sue A., "21st Century Anthropology Scholarship: A Citation Analysis" (2020). University Libraries Faculty Scholarship. 142.

https://scholarsarchive.library.albany.edu/ulib_fac_scholar/142

This Article is brought to you for free and open access by the University Libraries at Scholars Archive. It has been accepted for inclusion in University Libraries Faculty Scholarship by an authorized administrator of Scholars Archive. For more information, please contact scholarsarchive@albany.edu. 


\section{$21^{\text {st }}$ Century Anthropology Scholarship: A Citation Analysis}

PRISCILLA SEAMAN

University at Albany, Albany, New York

SUE A. KACZOR

University at Albany, Albany, New York

Address correspondence to Priscilla Seaman, Subject Librarian, University at Albany, University Libraries, 1400 Washington Avenue, Albany, NY 12222. E-mail: pseaman@albany.edu 
ABSTRACT. A 2017 citation study looked at four scholarly anthropology journals in order to evaluate current research trends. This study examined the following journals: Current Anthropology, the American Anthropologist, the American Ethnologist, and the Journal of Anthropological Research. The results showed an average of 89.9 citations per article, which is a large increase over previous studies. The breakdown by the largest two categories showed $48.1 \%$ citations to total books, compared to $41.2 \%$ for scholarly journals. All other source types of citations comprised only $10.7 \%$ of total citations. These results were compared to a 2005 study by William Robinson and Paul Posten of the same four journals from 1999.

KEYWORDS. Anthropology journals, anthropology literature, bibliometrics, books, citation analysis, collection development 


\section{INTRODUCTION}

Anthropology is a broad subject area, comprised of four major fields of study: cultural/social anthropology, archaeology, linguistics, and physical anthropology. Anthropologists draw from a wide range of subjects, a point repeated throughout the literature (Hider 1997; Michalski 1999; Robinson and Posten 2005). The domain of anthropology crosses disciplines and academic categorization. David Michalski states "Although anthropology has traditionally been categorized as a social science, this dynamic field of inquiry draws on diverse and disparate sources, referencing and contributing to both the humanities and the physical sciences" $(1999,1)$.

When examining the library science literature, there are two basic approaches in conducting a citation analysis. The first is a study of local patterns in use by faculty and students in books, journal articles or dissertations/theses. The second focuses on the study of the broader discipline by studying literature in a field. When looking at a broadly based analysis of a subject like anthropology, larger patterns can be discerned which help to inform local decision-making in collection development, information literacy, and discipline-specific research assistance. William Robinson and Paul Posten's 2005 journal article entitled, Literature Use of Scholars Publishing in Leading Anthropology Periodicals, served as the inspiration for this current study. Their citation analysis conducted in 1999, examined four core anthropology journals with a cultural/social focus. The authors of this paper compare selected findings with those of Robinson and Posten, examining changes that have taken place since 1999, when the switch to online journals was just starting. By 2017, the year of this study, a seismic shift had occurred with the vast majority of journals available online. Additionally, library circulation statistics for print materials like books have continued to trend downward, begging questions of whether and how books are used in $21^{\text {st }}$ century anthropology scholarship. 
The authors studied current patterns of anthropology literature use, as discerned from citation analysis of the four anthropological journals that were the subject of the prior Robinson and Posten research. The key questions for this present study are:

- What was the pattern of use of books/monographs compared to scholarly journals? How did this compare to use in $1999 ?$

- What types of resources were cited by authors in the four scholarly anthropology journals?

- What broader citation patterns can be discerned in the anthropological literature?

\section{LITERATURE REVIEW}

The following literature review presents descriptions of bibliometric studies, surveys, and research articles that examine literature use in anthropology, its subdisciplines, and cognate fields. The literature review addresses two themes central to this study: 1) patterns and characteristics of anthropology scholarship, and 2) citation analyses of anthropology scholarship, specifically ones that compare book and journal use.

In examining patterns and characteristics of anthropology scholarship, the literature revealed three related findings: a higher than average citation count per article when compared with related disciplines; a vast amount of available information; and subject dispersion due to the broad and interdisciplinary nature of anthropological research.

Higher than average citation counts were reported in an early analysis of core anthropology journals (Garfield 1984). Garfield concluded that anthropology sets itself apart by citing approximately 30\% more references when compared with other social science disciplines. Later studies quantified citation counts per article. Robinson and Posten (2005) found 
approximately 44 citations per article in their analysis of four anthropology journals published in 1999. In a study of anthropology faculty publications at the University of Notre Dame, researchers found the average number of citations per article was 42 in a ten-year period from 1998-2008; within the five-year range of 2003-2008, the average number of citations per article rose to 46 (Kayonga and Helm 2009).

David Michalski $(1999,3)$ observed a pattern related to high citation counts in which he described a "vast literature" and an "explosion of information" within the field of anthropology. The author speculated that this vast literature was partly the result of new technologies and the rise of cultural studies in anthropology. Indeed, the year of his article closely coincided with the emergence of the information age and the advancement of computer technologies both of which transformed scholarship. Michalski further described anthropology as a "fragmented discipline" with a long history of connection to and rootedness in other subjects, one in which "the providence of bibliographic control" had contributed to its fragmentation (Michalski 1999, 2).

The broad nature of anthropological research is described throughout the literature, notably by Robinson and Posten $(2005,15)$ who quantified anthropology's subject dispersion by analyzing the Library of Congress classification of cited literature. In their analysis, they determined that 82 different classes were used, representing a "wide range of materials from virtually all subjects." Despite this broad subject dispersion, they found that books and journals classified in anthropology constituted the majority of sources cited.

The interrelatedness of citing sources from a wide variety of disciplines, along with an "information explosion," and a tendency for higher citation counts within the field of anthropology, revealed a scholarship pattern unique to the discipline of anthropology. 
Another pattern revealed by the literature was the type of resource cited by anthropologists. Bruce Bachand (2013) uncovered unique disciplinary research traits by analyzing and describing types of libraries that specialize in anthropology research. He investigated 27 major specialized anthropology libraries categorized by library type: museum/department, government, private/specialized. Bachand concluded that physical collections of books and materials were highly important to anthropologists, particularly to cultural and archaeological research. Among the other material types mentioned were gray literature, site reports, maps, sound recordings, art catalogs, lexicons, grammars, field notes, rare books, visual materials, and foreign-language books.

One study drew similar conclusions to Robinson and Posten about types of materials cited (Brughmans 2013). In a large-scale citation network analysis of archaeological publications, the researcher found that books and older materials are frequently cited, while government documents, gray literature and museum publications are rarely cited. Brughmans further discussed some limitations of Web of Science in its lack of indexing of books and nonEnglish-language publications.

Ifeanyi Ezema and Brendan Asogwa (2014) observed that the tools used to conduct citation analyses, such as Web of Science, tend to skew in favor of the sciences, Englishlanguage publications, and European and North American sources. In their citation analysis of two linguistic journals, they discussed historical contentions of how to classify linguistics and whether it belongs to either the humanities or to the sciences. The studies of Ezema and Asogwa, Brughmans, and Bachand highlighted anthropological subdisciplinary characteristics, and provided examples of ways in which classification and scholarship patterns differ among the 
subdiscplines of anthropology. They offered food for thought on how subdisciplinary uniqueness might affect overall scholarship patterns within anthropology.

Similar to the findings of Bachand and Michalski, Celia Emmelhainz (2015) noted that anthropological research necessitates finding unique and unconventional source types that may not be indexed in traditional library search tools and databases. Emmelhainz studied the information seeking behaviors of expatriate social scientists in Kazakhstan. Her study found that anthropology scholars not only needed source types beyond books, monographs and journals, but their cross-cultural and ethnographic research expanded their information needs beyond the traditional library.

A second study published by Emmelhainz and Estrada (2017) examined the indexing of recent publications by anthropology faculty at the University of California at Berkeley. They discovered that anthropology publications are indexed in a variety of databases and Google Scholar, and that discipline-specific databases did not necessarily yield the most fruitful results. They pointed out the difficulties of anthropological research, with its subfields and subject dispersion, noting the importance of books and book chapters, the indexing of which were commonly excluded in many databases.

The second theme of anthropology scholarship revealed by the literature review was book, journal, and other source use determined through citation analyses. A chronological review of these citation analyses follows.

An early study of anthropological references in the Indian journal, Man in India, was conducted by R.P. Rana (1982). Rana examined references in the ten-year period from 19701979. She determined that books comprised the largest percentage of references at $51.7 \%$, while journals articles comprised $33.2 \%$. 
In the only study to find higher journal citation counts than books, Jin M. Choi (1988) compared references in the 1963 and 1983 volumes of core American anthropology journals. Choi determined that citations to journals (52.2\%) outnumbered books (45.3\%) in 1963 and also in 1983 , (journals at $51.8 \%$, books at $41.0 \%$ ).

P. Aravinda and V. Pulla Reddy (1990) looked at cited articles in the journal, Annual Review of Anthropology, from the period 1980-1982. Contrary to Choi's study, they found a higher number of references to books (57.5\%), while references to journal articles were $37.2 \%$. Perhaps the differences between the conclusions of the studies could be accounted for, in part, by the number of socio/cultural journals employed. Aravinda and Reddy selected just one journal, as opposed to Choi's choice of multiple anthropology journals that represented a broader coverage of anthropology subdisciplines.

Philip Hider (1997) conducted a bibliometric analysis of materials cited a in a 27-year year period (1966-1993) in Man, a core British anthropology journal. Hider concluded that whole books constituted the majority of literature cited. In his study, citations to books (53\% in 1966 and 72\% in 1993), increased over time. During the same time-period, citations to serials decreased (43\% in 1966 and 25\% in 1993). Hider's findings for the year 1993 represented the largest gap in numbers of cited books and journals of reviewed articles.

While previous analyses examined either single journal titles or multiple journals over time, Robinson and Posten (2005) conducted a deep analysis of citations (and other scholarship patterns) of four anthropology journals in the one-year period of 1999. For that year, they concluded that anthropology scholars cite books (58\%) more often than journals (33\%).

While the following study did not specifically look at citation patterns, it nevertheless quantified book and journal use among anthropologists by using library circulation counts as a 
measure. A survey of scholars' self-reported book and journal use in four social science disciplines at the University of Illinois at Urbana-Champaign found that anthropology scholars borrowed a higher number of books and monographs (mean=54) from the library than the other three disciplines (mean=23) (psychology, sociology and social work). The study further noted that the subfields of anthropology that are more oriented toward the humanities, such as cultural anthropology, indicated different patterns of scholarly communication and literature use (Sutton and Jacoby 2008).

An analysis of anthropology faculty publications at the University of Notre Dame found a narrower gap between books (47\%) and journals (45\%) than most previous citation studies (Kayonga and Helm 2009).

In the final citation analysis reviewed, researchers analyzed references from two linguistics journals over a ten-year period from 2001-2010. They found that references to books and monographs dominated with an average of $53.3 \%$, while journals constituted $35.9 \%$ of the total citations (Ezema and Asogwa 2014).

Seven out of eight citation analyses and studies reported higher book use than journal use among anthropology scholars. Among those seven studies, the gap between the number of citations to books and journals ranged from $2 \%$ to $47 \%$, with an average of $20.2 \%$ more books cited than journals. Differences among the studies could be attributed to the broader or more narrow focus of selected journals and the subdisciplines represented in citation counts.

\section{METHODS}

For the purpose of this study, the four scholarly journals used in the 2005 Robinson and Posten article were selected, which allowed specific comparisons over time. These journals are 
American Anthropologist (AA), American Ethnologist (AE), Current Anthropology (CA), and Journal of Anthropological Research (JAR).

A brief description, adapted from Magazines for Libraries (2018), of each journal follows:

American Anthropologist is the flagship journal of the American Anthropological Association and publishes research articles on all facets of anthropological knowledge. American Ethnologist is international in scope and presents a broad overview of ethnology and ethnographic research. The journal features original research on topical cultural events and concerns.

Current Anthropology, published by the University of Chicago, is a transnational journal devoted to research on humankind, including social, cultural, and physical anthropology, as well as ethnology, archaeology, folklore, and linguistics.

The Journal of Anthropological Research publishes peer-reviewed research articles on recent research findings in ethnology, archaeology, biological anthropology, and linguistic anthropology.

All regular issues for the year 2017 were included, excluding special issues. Special issues were excluded because they focused on specific topics, not all of which were research articles. Only research articles were analyzed for the purposes of this study. The reference list/bibliography for each journal article was compiled and analyzed for patterns, using a Microsoft Excel spreadsheet.

Citations were evaluated and identified by one of (9) categories: whole books, book chapters, scholarly journals, working papers, popular periodicals, government publications, organization publications, web publications, and other/unknown. These nine publication types 
generally mirrored categories selected by Robinson and Posten with the subtraction of the category for museum publications, and the addition of categories for popular periodicals and web publications. An early analysis of this present study found a lack of citations to museum publications. The authors noted the presence of citations to web publications and popular periodicals, warranting a closer look at these potentially newer citation types. Citations for books were broken into two categories, depending on whether the citations referred to the entire book or to a chapter within a book. Items identified as working papers included dissertations, theses, conference presentations and forthcoming materials. The categories of popular periodicals and web publications were added in this study to investigate potential changes in $21^{\text {st }}$ century literature use trends, answering questions of whether widely available and easily accessible popular publications appear more frequently in references, and whether some publications are only recognizable as web publications. Popular periodicals included newspapers and general news magazines. Web publications included web pages, webzines and web news. A final category called other/unknown included cited materials that did not fit into any of the above categories, such as films, and those references for which sufficient information was not available to assign a category, or for which the authors could not identify a category, such as a few foreign language citations.

\section{RESULTS}

\section{General Findings}

For the year 2017, there were a total of 18 regular issues in the four anthropology journals in this study. These issues contained a total of 108 research articles. (Table 1.) The number of articles in journals ranged from16 in Journal of Anthropological Research to 35 in the American 
Ethnologist. For comparison, the study by Robinson and Posten (2005) covered 79 selected articles published in 1999. In their study, JAR also had the smallest number of articles (10), but the journal with the largest number of articles was $C A(29)$.

The average number of pages increased slightly for two journals ( $A A$ and $J A R$ ), significantly for $C A$, and decreased for $A E$ compared to the Robinson and Posten study. However, the average length of article among the four journals has remained quite consistent. Robinson and Posten found that the average article was 18 pages long, while this study found the average length of article at 20 pages.

As shown in Table 1, there were 9,468 total citations evaluated in this study. The fewest total citations were in $J A R(1,424)$, while $C A$ had the most total citations $(3,443)$. These figures partly reflect the number of articles in these publications, with $J A R$ also having the fewest number of articles. In contrast, $C A$ had the second smallest number of articles while having the most total citations. In the Robinson and Posten study, JAR also had the fewest total citations, with $C A$ having the most. For this particular measure, little has changed over the ensuing years.

\section{Analysis of Citations}

The average number of citations per article within a particular journal title ranged from a low of 63 citations $(A E)$ to a high of 128 citations $(C A)$, with an average of 89.9 citations per article (Table 2). In contrast, the 2005 article by Robinson and Posten $(2005,9)$ found “...between 37 and 42 references" per article (or an average of 44.1 citations per article). This number is less than half the number found in the current study. The authors hypothesize that this could in part be explained by the methodology that Robinson and Posten used. They selected "every other article with references," possibly resulting in the inclusion of non-research articles with lower number of citations per article. However, Robinson and Posten's average number of citations is 
similar to averages of other anthropology bibliometric analyses of the time. For example, Kayonga and Helms' $(2009,92)$ analysis of anthropology journals from the years 1998-2008, found an average of 43 citations per article.

Difference in citation counts can also reflect the science, social science or humanities slant of a particular discipline. For example, an article on two linguistics journals by Ezema and Asogwas $(2014,67)$ found “ $\ldots$ an average of 17.2 citations per paper.” This is a much smaller number than the average found in this study. Earlier studies point to the need to more closely study differences in literature use and citation patterns among the subdisciplines of anthropology (Bachand, 2013, 189; Robinson and Posten, 2005, 15). Regardless of the lack of subdisciplinary studies, the results of this study show a significant increase in the average number of citations per article when compared with earlier studies, perhaps due to increased electronic search capabilities since 1999.

When analyzing the data for the largest citation categories, books and book chapters totaled 4,555 citations, or $48.1 \%$ of the total citations. In comparison, scholarly journals made up 3,897 of the citations, or $41.2 \%$ off the total citations. Together, they accounted for $89.3 \%$ of the total citations. (Graph 1.) Robinson and Posten $(2005,1)$ found that total books comprised around $58 \%$ of the citations, while $33 \%$ were to periodicals, making up about $91 \%$ of the total. To analyze total books further, citations to book chapters accounted for $13.5 \%$ of total citations in this study while whole books accounted for $34.6 \%$. The authors hypothesized that citations to book chapters might actually increase over time as online access through databases and eBooks made them more findable, but instead, this number actually represents a decrease of $2.3 \%$ compared with Robinson and Posten. 
To explore relationships between total citations of books and scholarly journal articles, by journal title (Table 4 ), the numbers were evaluated using a chi-square test, at 5\% significance. The chi-square test showed that there was a statistical difference between total numbers of books, when broken down by journal title. Examination of the data suggests that $C A$ had significantly greater total numbers of citations for books than the expected value, while $J A R$ had significantly less.

When the same statistical test was used to evaluate numbers of citations to scholarly journal citations, the chi-square test once again showed a statistical difference between some of the journal titles. The data show that $C A$ had significantly higher total numbers of citations for scholarly journal articles.

The other six categories made up the last $10.7 \%$ of the citations. Of these six categories, the category of working papers made up the largest segment, comprised of conference papers, dissertations, theses, and items labeled in citation lists as "forthcoming." It was intriguing to see that only $0.7 \%$ of the citations in this study could be classified as web publications. Robinson and Posten commented that their research showed “... little use of digital information" (2005, pg. 1). In the ensuing time period, the authors hypothesized that this might have changed, but the results of this study did not support this.

\section{CONCLUSIONS AND DISCUSSION}

By selecting the same four journals used by Robinson and Posten, this study sought to update sections of their study, giving special attention to source type. Of particular interest was the use of books compared with scholarly journals. This study found an eleven percent decline in overall book use (books and book chapters), and an approximate eight percent increase in scholarly 
journal use in the 18 years since the Robinson and Posten study. While these figures represent a noteworthy change over time, book use continues to be the predominant source type used by anthropologists in the first decades of the $21^{\text {st }}$ century. Before undertaking this study, the authors assumed that the percentage of books would have dropped drastically, but this was not the case. These assumptions were based on library circulation statistics, (mis)conceptions that book use is secondary to other sources, and the wide availability of journal literature via academic databases and the internet. The results of this study more closely resemble the results of Kayonga and Helm's analysis (2009) in which they found book use to be at $47 \%$ and journal use $45 \%$ among Notre Dame anthropology faculty. Previous studies (Bachand, 2013; Brughmans, 2013; Robinson and Posten, 2005) point to the heavy reliance of book use among anthropology scholars, a trend that continues in this new century. It will interesting to track book use trends into the future as more libraries focus on the acquisition of eBooks, perhaps becoming more discoverable online, but less available through restrictive license agreements and interlibrary loan policies.

Anthropology can be difficult to categorize due to its uniquely interdisciplinary nature. Historically, anthropology has been rooted in geography, biology, and more recently the social sciences and humanities. By all descriptions, anthropology spans the three broad areas into which academic disciplines are categorized -- the humanities, social sciences, and sciences. Robinson and Posten concluded that the literature use patterns of anthropology show a strong similarity to literature use in the humanities. This pattern could be shifting slightly in the early $21^{\text {st }}$ century. One cause of this potential shift is an increase in articles concerning physical anthropology due to a perceived uptick in human biology programs across colleges and universities. However, a follow-up study is needed to determine if this theory bears weight. 
Robinson and Posten sought to control for literature use differences among the subdisciplines by selecting journals with a socio-cultural focus. The authors of this study informally observed a similar predominance of socio-cultural articles. A closer scrutiny of article focus could provide more nuanced information on citation patterns.

The category other than books and journals that comprises $10.7 \%$ of the total sources closely corresponds with the findings of Robinson and Posten's remaining categories. They found about $10 \%$ of sources other than books and journals, while Rana found $15.1 \%$ other sources. These sources should not be overlooked. Anthropology scholarship can necessitate sources not typically studied or traditionally indexed. Aside from the sources identified in this study such as organization and government publications, other rarer materials included gray literature, films, field notes, sound recordings, and maps. While the "other/unknown" category into which many of these sources fall is only $1.1 \%$ of total sources, these rich and unique materials can impart invaluable information to the anthropology scholar. It is important to keep in mind the international, interdisciplinary, and subject diverse aspects of the study of anthropology and the corresponding need for diverse source types.

The most surprising result of this study was the dramatic increase in number of citations per article. This study found twice the number of citations per article compared with Robinson and Posten's journals published 18 years ago, and twice the number of all reviewed studies of anthropology literature use. The increase in number of citations per article could reflect increased availability of materials in the internet age. It could also reflect increased discoverability and connectedness of sources through citation databases such as Web of Science and Google Scholar. On the other hand, the large number of citations per article could be a continuation of anthropology scholarship patterns identified as early as 1982 when anthropologists were found to 
cite $30 \%$ more sources than other scholars (Garfield, 1984). Michalski alludes in to an "information explosion" in anthropology in his 1999 article. Whatever the reasons and causes of this vast increase in numbers of citations per article, further study is needed and comparison with the citations patterns of related disciplines could prove insightful.

The results of this study provide food for thought when managing collections. In spite of pressure on libraries to increase their access to journal collections, individual journals and individual articles, books supporting anthropology appear to require equal consideration. The importance for resource sharing among libraries is supported by the high book use and high citation counts of anthropologists. In addition, an awareness of specialized anthropology collections is important in serving anthropology scholars. Lastly, the authors caution against drawing broad conclusions; acquisition of materials must also consider local programs of study, focus of scholars, and curricular needs.

Finally, a note on the methodology. As opposed to using a software or text-mining program to extract citation information, this study employed a hands-on approach of examining each citation of every selected journal research article. While time-consuming, this approach yielded tangential benefits of exposure to authors, article titles, and article content. A familiarity with current anthropological topics and frequently cited authors was developed along with a deepened understanding of current anthropological scholarship. As with all research, the development and deepening of understanding leads to inspirational thoughts, further questions, and begs the continuation of discussion through future investigation and study.

\section{Acknowledgements}

A special thanks to Bruce Conrad for his help with numbers in Excel, and to John Wuthrich for his help with statistical analysis. 


\section{REFERENCES}

Aravinda, P. and V. Pulla Reddy. 1990. Citation analysis of sociocultural anthropology literature. Lucknow Librarian 22: 51-57.

Bachand, Bruce R. 2013. Anthropology libraries and anthropological research today. Behavioral \& Social Sciences Librarian 32 (3):176-193.

Brughmans, Tom. 2013. Networks of networks: A citation network analysis of the adoption, use, and adaptation of formal network techniques in archaeology. Literary and Linguistic Computing 28 (4):538-562.

Choi, Jin M. 1988. An analysis of authorship in anthropology journals, 1963 and 1983. Behavioral \& Social Sciences Librarian 6 (3-4):85-94.

Emmelhainz, Celia. 2017. Supporting the expatriate social scientist: Faculty research and information access in post-Soviet Kazakhstan. Journal of Librarianship and Information Science 49 (1):69-81.

Emmelhainz, Celia and Natalia Estrada. 2018. Searching for recent anthropology and archaeology publications. ANSS Currents 33 (1):17-21.

Ezema, Ifeanyi J. and Brendan E. Asogwa. 2014. Citation analysis and authorship patterns of two linguistics journals. Portal: Libraries and the Academy 14 (1):67-85.

Garfield, Eugene. 1984. Anthropology journals: What they cite and what cites them. Current Anthropology 25 (4):514-528.

Hartmann, Jonathan. 1995. Information needs of anthropologists. Behavioral \& Social Sciences Librarian 13 (2):13-34.

Hider, Philip M. 1997. Three bibliometric analyses of anthropology literature. Behavioral \& Social Sciences Librarian 15 (1):1-17. 
Kayongo, Jessica and Clarence Helm. 2009. Citation patterns of the faculty of the Anthropology Department at the University of Notre Dame. Behavioral \& Social Sciences Librarian 28 (3):87-99.

Michalski, David. 1999. The predicament of anthropology: Reference support in a fragmented discipline. Katherine Sharp Review 8 (Summer):1-4.

Rana, R.P. 1982. A trend in citation pattern in anthropology. Annals of Library Science and Documentation 29 (4):170-177.

Robinson, William C. and Paul E. Poston. 2005. Literature use of scholars publishing in leading anthropology periodicals. Behavioral \& Social Sciences Librarian 23 (2):1-17.

Seaman, Priscilla. 2018. Anthropology. In Magazines for Libraries, edited by Cheryl LaGuardia. 27th edition, 60-64. New Providence, NJ: ProQuest.

Sutton, Allison M. and JoAnn Jacoby. 2008. A comparative study of book and journal use in four social science disciplines. Behavioral \& Social Sciences Librarian 27 (1):1-33. 


\section{Tables and Graphs}

Table 1. Journal Characteristics (Totals).

\begin{tabular}{|l|r|r|r|r|r|}
\hline & $\begin{array}{r}\text { American } \\
\text { Anthropologist } \\
\text { (AA) }\end{array}$ & $\begin{array}{r}\text { American } \\
\text { Ethnologist } \\
\text { (AE) }\end{array}$ & $\begin{array}{r}\text { Current } \\
\text { Anthropologist } \\
\text { (CA) }\end{array}$ & $\begin{array}{r}\text { Journal of } \\
\text { Anthropological } \\
\text { Research (JAR) }\end{array}$ & Totals \\
\hline Total articles & 30 & 35 & 27 & 16 & $\mathbf{1 0 8}$ \\
\hline Total pages & 414 & 440 & 611 & 484 & $\mathbf{1 , 9 4 9}$ \\
\hline $\begin{array}{l}\text { Total } \\
\text { citations }\end{array}$ & 2,401 & 2,200 & 3,443 & 1,424 & $\mathbf{9 , 4 6 8}$ \\
\hline
\end{tabular}

Table 2. Journal Characteristics (Averages).

\begin{tabular}{|l|r|r|r|r|r|}
\hline & $\begin{array}{r}\text { American } \\
\text { Anthropologist } \\
\text { (AA) }\end{array}$ & $\begin{array}{r}\text { American } \\
\text { Ethnologist } \\
\text { (AE) }\end{array}$ & $\begin{array}{r}\text { Current } \\
\text { Anthropologist } \\
\text { (CA) }\end{array}$ & $\begin{array}{r}\text { Journal of } \\
\text { Anthropological } \\
\text { Research } \\
\text { (JAR) }\end{array}$ & Average \\
\hline $\begin{array}{l}\text { Average } \\
\text { pages per } \\
\text { article }\end{array}$ & 13 & 13 & 23 & 30 & $\mathbf{2 0}$ \\
\hline $\begin{array}{l}\text { Average } \\
\text { citations per } \\
\text { article }\end{array}$ & 80.0 & 62.9 & 127.5 & 89.0 & $\mathbf{8 9 . 9}$ \\
\hline
\end{tabular}

Graph 1. Source Type Summary.

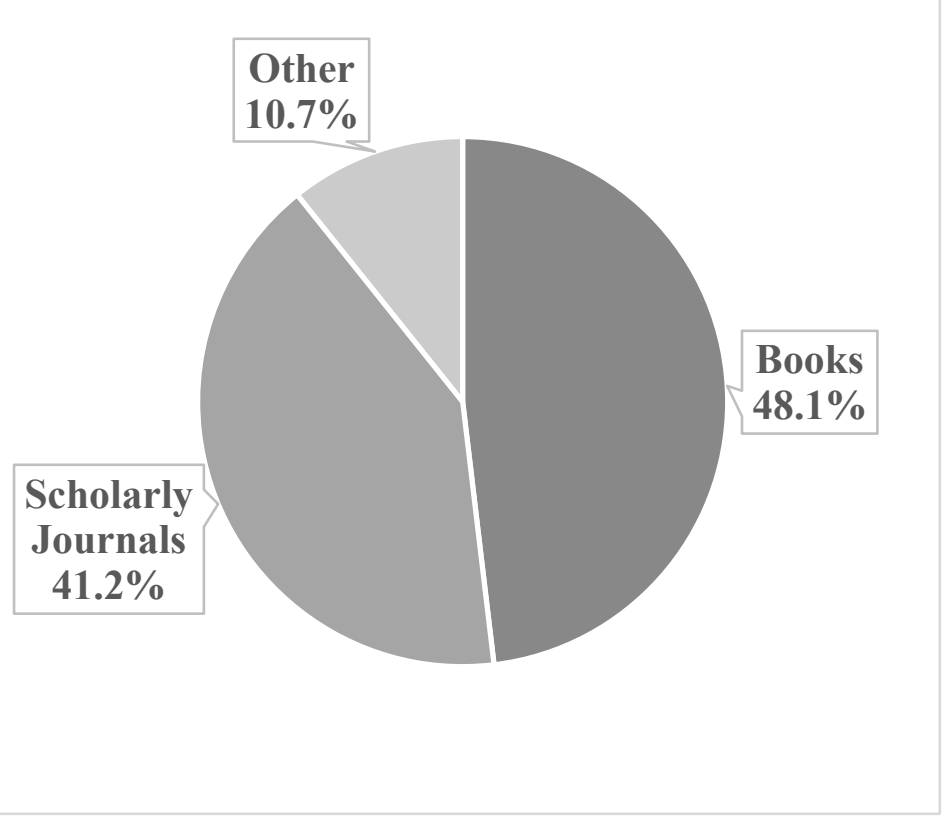


Graph 2. All Source Types

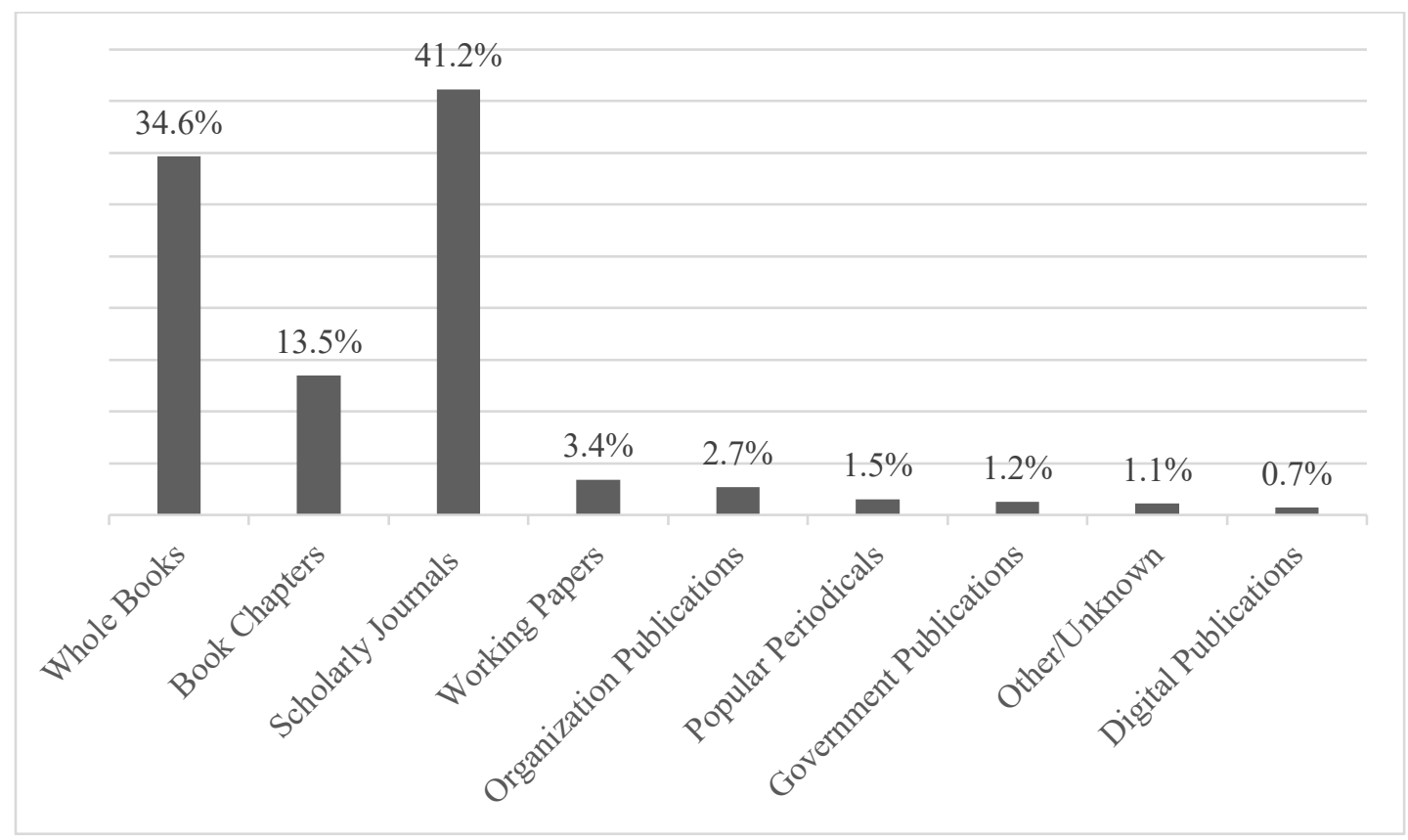

Table 3. Citation Characteristics by Percent.

\begin{tabular}{|l|r|r|r|r|r|}
\hline & AA & AE & CA & JAR & Average \\
\hline Whole Books & 31.0 & 46.0 & 34.9 & 22.6 & 34.6 \\
\hline Book Chapters & 14.3 & 9.5 & 14.2 & 16.4 & 13.5 \\
\hline Scholarly Journals & 44.7 & 32.0 & 41.3 & 49.1 & 41.2 \\
\hline Working Papers & 2.5 & 2.0 & 4.5 & 4.6 & 3.4 \\
\hline Popular Periodicals & 1.0 & 3.2 & 1.2 & 0.7 & 1.5 \\
\hline $\begin{array}{l}\text { Organization } \\
\text { Publications }\end{array}$ & 2.9 & 3.8 & 2.0 & 2.5 & 2.7 \\
\hline $\begin{array}{l}\text { Government } \\
\text { Publications }\end{array}$ & 1.7 & 0.7 & 0.6 & 2.9 & 1.2 \\
\hline Other/Unknown & 1.1 & 1.8 & 0.9 & 0.5 & 1.1 \\
\hline Digital Publications & 0.7 & 1.1 & 0.5 & 0.6 & 0.7 \\
\hline & & & & & \\
\hline Totals & $\mathbf{1 0 0 . 0}$ & $\mathbf{1 0 0 . 0}$ & $\mathbf{1 0 0 . 0}$ & $\mathbf{1 0 0 . 0}$ & $\mathbf{1 0 0 . 0}$ \\
\hline
\end{tabular}


Table 4. Citation Characteristics by Number.

\begin{tabular}{|l|l|l|l|l|l|}
\hline & AA & AE & CA & JAR & Totals \\
\hline Whole Books & 744 & 1012 & 1202 & 322 & $\mathbf{3 2 8 0}$ \\
\hline Book Chapters & 344 & 209 & 488 & 234 & $\mathbf{1 2 7 5}$ \\
\hline Scholarly Journals & 1074 & 703 & 1421 & 699 & $\mathbf{3 8 9 7}$ \\
\hline Working Papers & 61 & 44 & 154 & 66 & $\mathbf{3 2 5}$ \\
\hline Popular Periodicals & 24 & 70 & 41 & 10 & $\mathbf{1 4 5}$ \\
\hline $\begin{array}{l}\text { Organization } \\
\text { Publications }\end{array}$ & 69 & 84 & 69 & 35 & $\mathbf{2 5 7}$ \\
\hline $\begin{array}{l}\text { Government } \\
\text { Publications }\end{array}$ & 41 & 15 & 20 & 42 & $\mathbf{1 1 8}$ \\
\hline Other/Unknown & 18 & 24 & 17 & 9 & $\mathbf{6 8}$ \\
\hline Digital Publications & 26 & 39 & 31 & 7 & $\mathbf{1 0 3}$ \\
\hline & & & & & \\
\hline Totals & 2401 & 2200 & 3443 & 1424 & $\mathbf{9 4 6 8}$ \\
\hline
\end{tabular}

Graph 3. Books/Scholarly Journals by Journal.

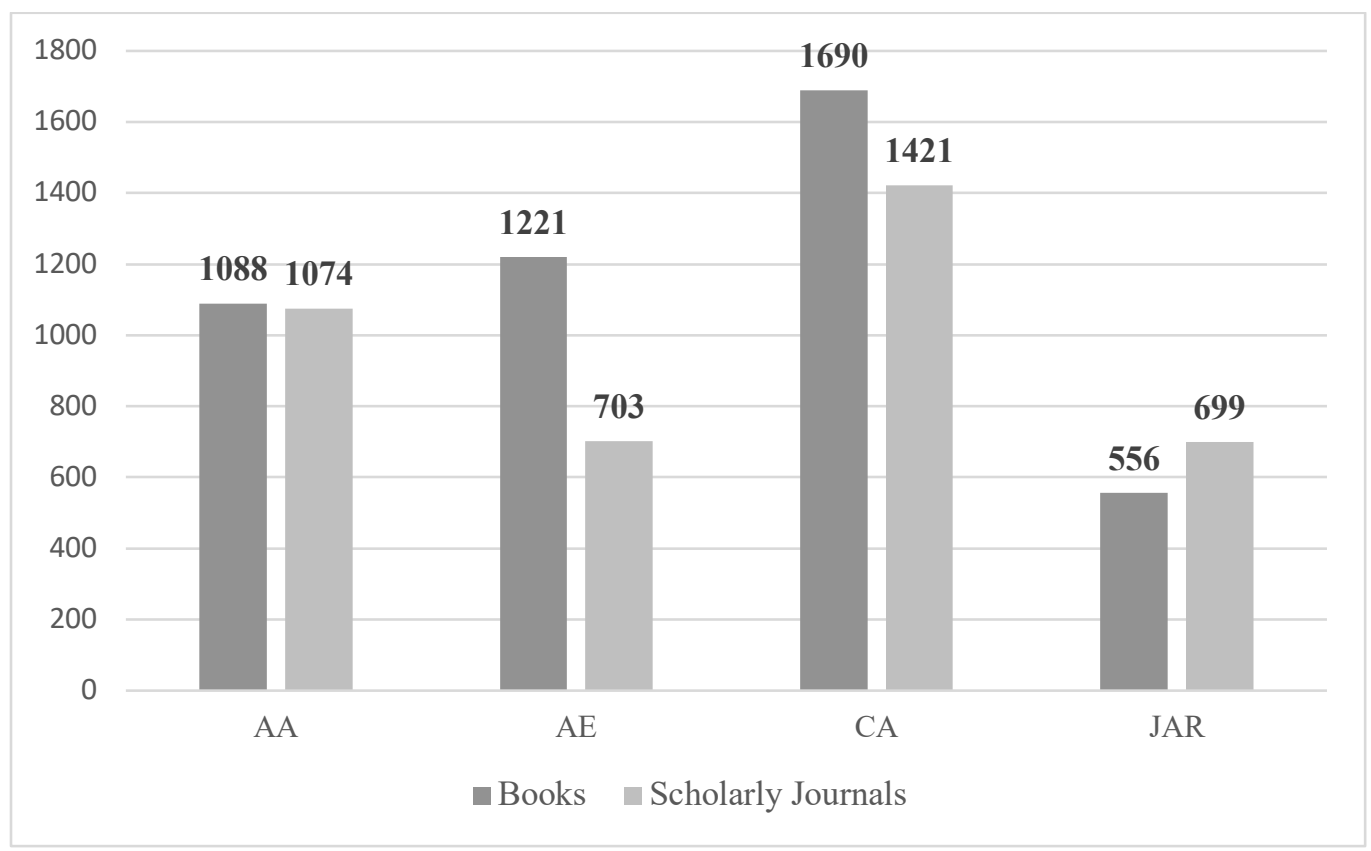

